\title{
An Intrinsic Time Limit between Genesis and Death of Individual Neurons in the Developing Retinal Ganglion Cell Layer
}

\author{
Lucia Galli-Resta and Monica Ensini \\ Istituto di Neurofisiologia, Consiglio Nazionale delle Ricerche, Pisa, Italy
}

\begin{abstract}
We tested the possibility that a temporal relationship exists between genesis and death of individual neurons dying during development. For this purpose, we labeled neurons born in limited time intervals and determined when they die in the ganglion cell layer (GCL) of the rat retina. We found that most neurons that die do so within a maximal interval of $5 \mathrm{~d}$ after their birth, irrespective of the age of genesis or of the cell type. These findings suggest the existence of a cellular clock regulating neuronal death during development.
\end{abstract}

We found also that neurons migrate in no less than $3 \mathrm{~d}$ to the $\mathrm{GCL}$, where a majority of cells that die remain a maximum of 2 d. This fast cellular turnover implies that the magnitude of neuronal death is far greater than previously believed.

Key words: cell death; cell genesis; retina; development; rat; retinal ganglion cells; displaced amacrine cells
Cell death has been recognized as an essential part of neuronal development since the first half of this century (for revicw, see Oppenheim, 1981). Decades of studies have led to the view that cell survival requires specific trophic factors that neuron acquire through cellular interactions in the period during which neuronal circuits are formed and refined (for review, see Purves, 1988; Oppenheim, 1991; Korsching, 1993). The mechanisms of neuronal death are still largely unknown. Recent studies, however, have made clear that in many instances intrinsic death programs are activated by the cells, which "kill" themselves in the absence of appropriate trophic support (Martin et al., 1988; Raff, 1992; Galli-Resta and Resta, 1992; Johnson and Deckwcrth, 1993; SilosSantiago et al., 1995). Within this framework, one would expect cell death to be regulated by cellular clocks. To approach this problem from a new perspective, we have analyzed whether a temporal correlation exists between genesis and death of individual neurons disappearing during development. For this purpose, in selected neuronal populations we have labeled neurons born within limited time windows and assessed how their number varied in time, to establish when the labeled cells die.

We have focused on the ganglion cell layer (GCL) of the rat retina, which consists of two neuronal populations, retinal ganglion cells and displaced amacrine cells (Perry, 1981). The GCL is particularly well suited for the present analysis because its sharp boundaries permit precise estimates of cell numbers. Furthermore, no newly born cells migrate through the GCL on their way to other locations, and no cells divide within this layer. These factors were prerequisites for the analysis used in the present study.

\footnotetext{
Received Nov, 3, 1995; revised Dec. 22, 1995; accepted Jan. 4, 1996.
}

We thank Bruna Margheritti and A. Bertini for technical assistance, P. Martini and M. L. Carrozza for critical reading of this manuscript, and Professors Y.-A. Barde and R. W. Oppenheim for useful comments. This work is dedicated to the memory of Professor R. Nobili.

Correspondence should be addressed to I.. Galli-Resta, Istituto di Neurofisiologia CNR, via San Zeno 5156127 , Pisa, Italy.

Dr. Ensini's present address: The Howard Hughes Medical Institute, Department of Biochemistry and Molecular Biophysics, Center for Neurobiology and Behavior, Columbia University, New York, NY 10032.

Copyright (c) 1996 Society for Neuroscience $0270-6474 / 96 / 162318-07 \$ 05.00 / 0$

\section{MATERIALS AND METHODS}

Experimental scheme. Cells of the retinal GCL born within limited time intervals were labeled with 5-bromo-2'-deoxyuridine (BrdU), which is incorporated in place of thymidinc by cells synthesizing DNA (Gratzner, 1982). Pregnant rats were administered BrdU to label cells in the retinae of rat fetuses. The retinae of one or more BrdU labeled pups (or fetuses) were analyzed at different ages to determine the number of labeled cells in the retinal GCL.

BrdU labeling. Two complementary procedures of BrdU administration were used: BrdU injection and BrdU pellet application. The combination of the two procedures allowed us to overcame the potential weakness of either method. BrdU injection provides a way to label cells born in a short interval, thus permitting a direct answer to the problem addressed in this study. However, BrdU injection has the drawback of a higher interindividual variability in counts of labeled cells when compared with pellets, and it introduces the difficulty of counting cells that are distributed with spatial gradients, as are cells generated on single embryonal days in the rat retina (Reese and Colello, 1992). BrdU pellets label cells born on intervals of several days, thus decreasing the time resolution of the study. However, the use of pellets greatly reduces interindividual variability (most likely because of time integration) and leads to a homogeneous distribution of labeled cells in the retina, thus allowing accurate estimates of cell numbers. In addition, BrdU pellets reduce (about threefold) the number of experimental animals required and permit the study of cells born during the same period in littermates that were all exposed at the same time and at the same dose of BrdU.

Surgical procedures and tissue preparation. Long-Evans hooded female rats were kept for $12 \mathrm{hr}$ with an adult male. The day of mating is embryonic day $0(E 0)$. At chosen gestational ages, pregnant dams were either injected with BrdU intraperitoneally $(50 \mathrm{mg} / \mathrm{kg}$ body weight; Bochringer Mannheim, Mannheim, Germany) or anesthetized with ether (anesthetic grade) for the application of a subcutaneous pellet of $\mathrm{BrdU}$ ( $50 \mathrm{mg} / \mathrm{kg}$ body weight). Whenever the study required the analysis of retinae from rat fetuses, the mother was anesthetized with Ketalar (ketamine chlorohydrate; Parke Davis Italia; $50 \mathrm{mg} / \mathrm{kg}$ body weight, i.m.), and fetuses were taken by hysterotomy while the mother's heart rate and temperature were kept under continuous control (see Galli and Maffei, 1988). Animals were killed by decapitation, and the eyes were quickly remuved and fixed by inmersion in $4 \%$ paraformaldehyde in $0.1 \mathrm{~m}$ phosphate buffer. Routinely, retinae were dissected and mounted flat.

$B r d U$ detection. Detection of BrdU with a monoclonal antibody (Boehringer Mannheim, dilution 3:200), a secondary biotinylated antibody (1:200), and the $\mathrm{ABC}$ peroxidase (both from Vector Laboratories, Burlingame, CA) method (intensified with nickel) allowed us to keep experimental variability within $20 \%$, in all but one case (see Results). Alternative methods gave more variable results (data not shown). Briefly, 
immunohistochemistry was performed as follows. After a pretreatment with sodium metaperiodate to block endogenous peroxidases, DNA was denatured in $\mathrm{HCl} 2 \mathrm{~N}$ for $30 \mathrm{~min}$ at $37^{\circ} \mathrm{C}$. After $5 \mathrm{~min}$ incubation in borate huffer, $\mathrm{pH} 8.5$, whole-mount retinal immunohistochemistry was performed as described by Casini and Brecha (1991). This protocol allowed cells located as deep as the inner nuclear layer (INL), well beyond the GCL, to be labeled. All chemicals, unless otherwise specificd, were obtained from Sigma (St. Louis, MO).

Counting labeled cells and related errors. The total number of cells in a retina was determined by multiplying the retinal area and the average density of labeled cells determined in 32 sampling fields. Each flatmounted retina was drawn at a magnification of $20 \times$ with the aid of a camera lucida attachment to the microscope. In each drawing, we traced eight equally spaced straight lines from the papilla to the retinal border, and each line was subdivided into four equal segments. A sampling field was positioned at the center of each segment. In this way, different regions of the retina were sampled similarly in retinae of different sizes. Sampling fields were $125 \times 125 \mu^{2}$ so that, on average, $1 / 30$ of the total area was sampled. Labeled cells in each sampling field were drawn using a camera lucida at a $12.5 \times 100 \times$ magnification. Labeled cells werc counted with no attempt to discriminate based on labeling intensity. The total retinal area was determined by weighing a camera lucida drawing of the retina made on paper of known weight $/ \mathrm{m}^{2}$. Different drawings of the same retina differed in weight by $<3 \%$. The standard deviation of the cell density was propagated as error and reported whenever it exceeded interindividual variability.

Defining the birth interval of labeled cells. BrdU is incorporated by cells that synthesize DNA at the time of labeling, and it is then diluted by any subsequent cell division. Therefore, the sensitivity of the method used to detect BrdU determines the interval during which labeled cells are born. A labeled cell must derive from a labeled mitotic cell and vice versa; if a mitotic cell is not labeled, its two daughter cells cannot be labelcd. Therefore, the interval during which labeled cells are born corresponds to the interval during which labeled mitotic profiles are present. The minimal duration of the interval during which labeled cells are generated is the length of the S-phase. BrdU is incorporated by cells in any stage of S-phase, which will complete DNA synthesis and go through G2 before entering mitosis. Therefore, the first labeled mitotic cells will be observed after a delay of $\mathrm{G} 2$, the last after $\mathrm{G} 2+\mathrm{S}$. Because the S-phase lasts several hours in the rat retina (6-13 hr depending on the animal age; Denham, 1967) (L. Galli-Resta, unpublished observations), and because the gestational age was determined with a $12 \mathrm{hr}$ resolution, we searched for labeled mitotic profiles every 12-24 hr. Mitotic divisions mostly occur in the most scleral portion of the retina, which lines the pigment epithelium and is at the opposite side of the retina with respect to the GCL. Labeled mitotic profiles were searched throughout the most scleral zone of the proliferative zone in whole-mounted retinae. Toward the end of neurogenesis, mitotic profiles are occasionally observed in the INL (for review, see Robinson, 1991). Although amacrine cells and ganglion cells are unlikely to be generated in this zone (Robinson, 1991), we searched for labeled mitotic figures also in retinal cross-sections from E19 onward (4 sections/ retina). Approximately one labeled mitotic profile could be observed in the INL every 20 sections.

Counting labeled pyknotic cells. In retinae processed for BrdU immunohistochemistry and counterstained with cresyl violet, we determined the proportion of pyknotic cells (recognizable by their distinctive morphology) that were also BrdU-labeled. The same sampling procedure wats used as described for labeled cells. An average of 50 pyknotic cells was analyzed for the presence of BrdU per retina.

Counting labeted cells crossing the IPL. Hixed retinae were cryoprotected in $20 \%$ sucrose in phosphate buffer overnight. Cryostat sections (10 $\mu \mathrm{m}$ thick) were cut perpendicular to the retinal surface and immunoreacted for BrdU. Labeled cells crossing the inner plexiform layer (IPL) were counted under Nomarski optics throughout 32 retinal crosssections for each retina. Because different sections might undergo different degree of shrinkage after dehydration and staining, we expressed the number of labeled cells found in the IPL as percentage of the number of labeled cells in the GCL of the section, a measure largely independent of shrinkage.

Determining the cell composition of the single cohorts of labeled cells. We determined the composition of cell cohorts only in adult animals because any retrograde tracer used to label retinal ganglion cells selectively in newborn animals was degraded by the immunohistochemical procedure used to detect $\mathrm{BrdU}$. For this reason, it was not possible to distinguish retinal ganglion cells from displaced amacrine cells in each cohort at each developmental time point. For cach modality and age of BrdU administration, the number of labeled displaced amacrine cells was determined by sectioning intraorbitally the optic nerves of three rats, and waiting 90 d for ganglion cells to degenerate (Villegas-Perez et al., 1993). To estimate the number of labeled retinal ganglion cells, we obtained the difference between the total number of labeled cells found in the GCL of normal animals and the number of labeled displaced amacrine cells we obtained in animals with intraorbital optic nerve section. Optic nerve section was performed as described in Gravina et al. (1990).

\section{RESULTS}

In a first experiment, we labeled cells born within limited time intervals by injecting BrdU on E15 or on E17. In both cases, labeled mitotic profiles in the retina were only observed on the day of injection and on the next day. Thus, cells labeled after BrdU injection were born within a maximum of $48 \mathrm{hr}$ (Fig. 1a). In the GCL (which is $\sim 300 \mu \mathrm{m}$ away from the region where most mitotic divisions occur in the retina), labeled cells were first observed $3 \mathrm{~d}$ after BrdU injection. The number of labeled cells in the GCL increased during the next $24 \mathrm{hr}$, then dropped to a constant value $12 \mathrm{hr}$ later (Fig. 1b,c). Thus, a constant number of labeled cells was obtained within $4.5-5 \mathrm{~d}$ of cell genesis.

To strengthen the conclusions derived from BrdU injection experiments (see Materials and Methods), we performed a second experiment by administering BrdU as a pellet on E13, E15, E17, E19, or E21. This procedure labeled cells born within an interval of $5 \mathrm{~d}$ (possibly $6 \mathrm{~d}$ in the case of E13 labeling), as determined by analyzing retinae for the presence of labeled mitotic profiles (Fig. 2a) (this long birth interval is attributable both to longer availability of BrdU when administered as a pellet and to higher initial BrdU content in labeled cells; data not shown). Whenever assessed (E19 and E21: Fig. 2b; E13: not shown), the first labeled cells in the GCL were observed $3 \mathrm{~d}$ after BrdU pellet administration. The number of labeled cells in the GCL increased in the 9-10 d after BrdU application, then dropped to a constant value in an additional $1 \mathrm{~d}$, in all cases tested (Fig. 2b,c). Thus, the number of labeled cells became constant $5 \mathrm{~d}$ after the last labeled cells were generated.

A constant number of cells can either arise from a balance between new labeled cells arriving in the GCL and an equal number of labeled cells being eliminated, or correspond to the end of any detectable addition and elimination of labeled cells.

Addition and elimination of labeled cells can be monitored separately. Dying cells are recognizable by their distinctive pyknotic morphology, and numerous labeled pyknotic cells (up to $75 \%$ of the total number of dying cells) could be observed before, and at the time the number of labeled cells was maximal. However, no labeled dying cells were observed once the number of labeled cells was constant (Fig. 3).

Cell migration to the GCL could be monitored as cells crossed the IPL, a layer of cell processes detectable as early as E18 (Braekevelt and Hollenberg, 1970), which separates the GCL from the region where all mitotic divisions occur in the retina. Nearly as many labeled cells could be detected in the IPL as in the GCL in the initial phases, and numerous labeled cells in the IPL could be seen as long as the number of labeled cells in the GCL was increasing. However, no labeled cells were observed in the IPL once the number of labeled cells was constant in the GCL (Fig. 4).

It seems reasonable to conclude that death of labeled cells is over once their number is constant or, more precisely, that a great majority of the labeled cells that die do so before the total number of labeled cells is constant, because the experimental error could 


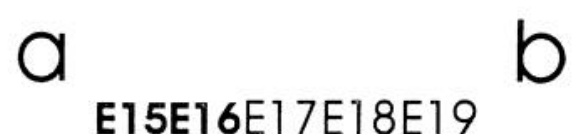

\section{E17E18E19}

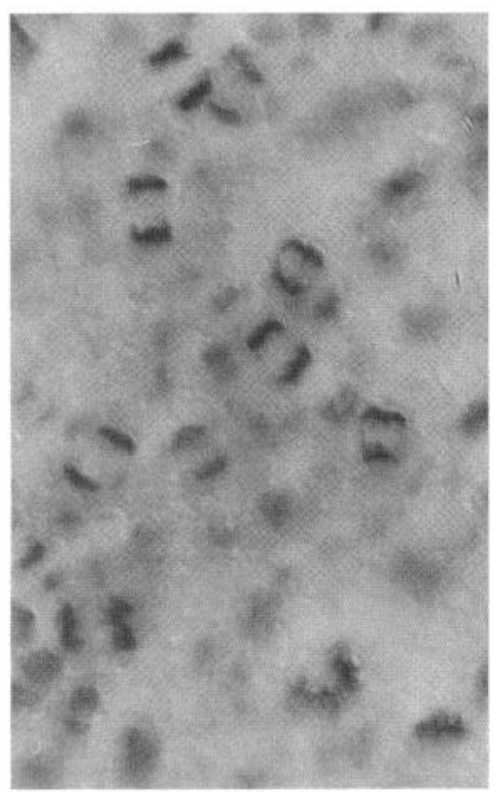

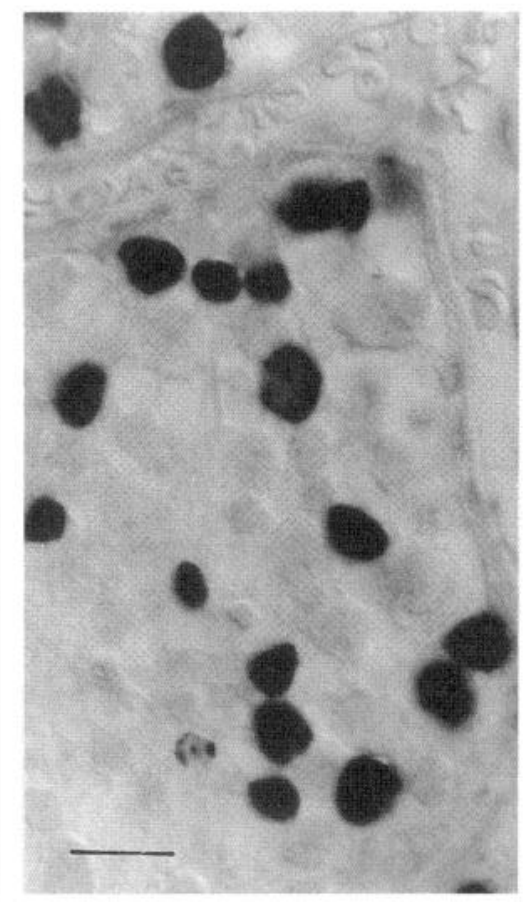
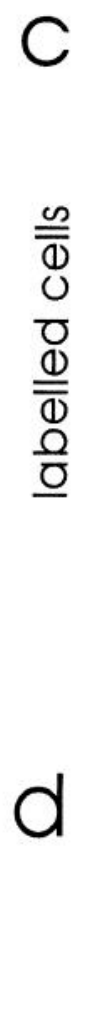

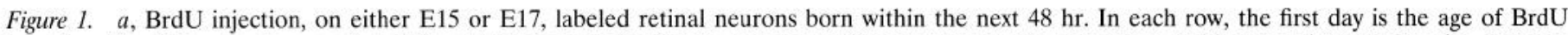

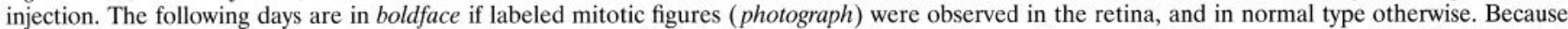

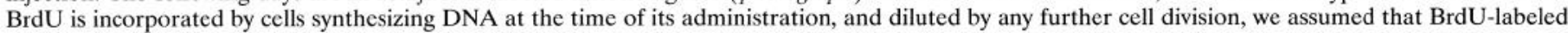

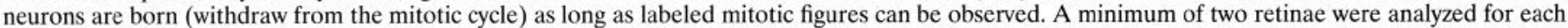

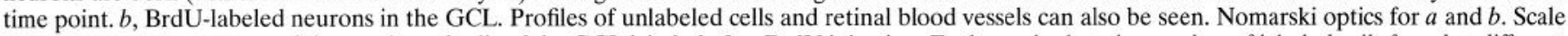

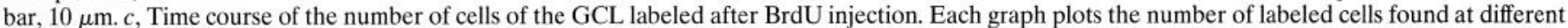

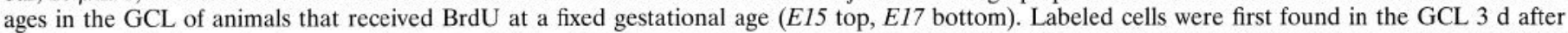

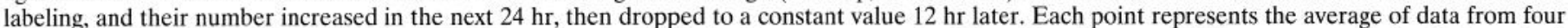

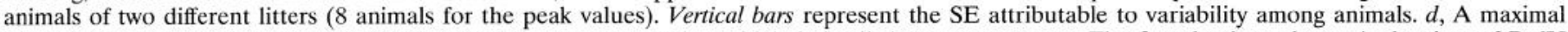

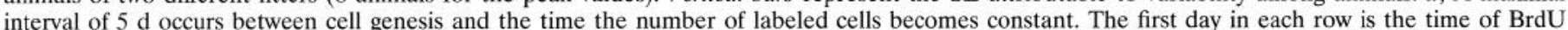

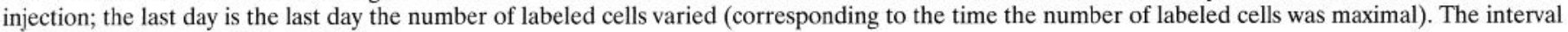
of labeled cell genesis is in boldface.

hide the later death of a small fraction of labeled cells $(<20 \%$; see Figs. 1, 2).

Therefore, a great majority of cells that die do so within $4.5-5$ $\mathrm{d}$ from their birth, as shown in Figure $1 c$. The results obtained with BrdU pellets (Fig. $2 b, c$ ) also show that most cells that die do so within $5 \mathrm{~d}$ of their genesis, as proven in the following considerations. Take for example the two cohorts of cells labeled by administering BrdU on E17 and E19, respectively. Cells of the E19 cohort born before postnatal day 1 (P1) are also comprised in the E17 cohort (Fig. 2a). Therefore, few of them can die beyond $\mathrm{P} 4$, because from P5 onward the E17 graph of Figure $2 b$ is constant. Only cells of the E19 cohort born on P1 and P2, which are not comprised in the E17 cohort (Fig. 2a), can die in great number on P5 and P6, as described by the E19 graph in Figure $2 b$ (see also Fig. 2c). Because similar considerations apply to all cohorts of labeled cells, we conclude that a great majority of cells that die do so within $5 \mathrm{~d}$ of their genesis, as found in the BrdU injection experiment.

We also investigated whether the cohorts of labeled cells comprised both types of neurons found in the GCL (Perry, 1981). Our analysis was limited to the composition of cell cohorts in adult animals (see Materials and Methods). We let a litter of animals reach maturity for each modality and age of BrdU administration.
In each case, the number of labeled displaced amacrine cells was determined by sectioning intraorbitally the optic nerves of three rats, and waiting $90 \mathrm{~d}$ for ganglion cells to degenerate (VillegasPerez et al., 1993). To estimate the number of labeled retinal ganglion cells, we determined the difference between the total number of labeled cells in the GCL of normal animals and the number of labeled displaced amacrine cells we obtained in animals with intraorbital optic nerve section. Figure 5 illustrates that different cohorts of labeled cells comprised different proportions of retinal ganglion cells and displaced amacrine cells, as expected from previous studies (Reese and Colello, 1992). Nevertheless, the $5 \mathrm{~d}$ limit between cell genesis and cell death applies to all cohorts. Therefore, it appears to apply to both retinal ganglion cells and displaced amacrine cells.

\section{DISCUSSION}

The results obtained in this study show that a majority of cells of the rat retinal GCL that die in development do so within $5 \mathrm{~d}$ from their genesis, independently of the time of their birth. This is the case for both retinal ganglion cells and displaced amacrine cells. Because newly generated cells migrate to the GCL in no less than $3 \mathrm{~d}$, most cells that die remain in the GCL no longer than $2 \mathrm{~d}$ (5 $-3=2$ ). Below we discuss the implications of these findings. 
E13...E15E16...E18...E20...E22P1P2P3..P5.. E15.........E19E20E21...P1P2P3P4P5P6

E17........E21E22P1P2P3P4P5P6

E19...E21E22P1P2P3P4P5P6

E21E22P1P2P3P4P5P6

○

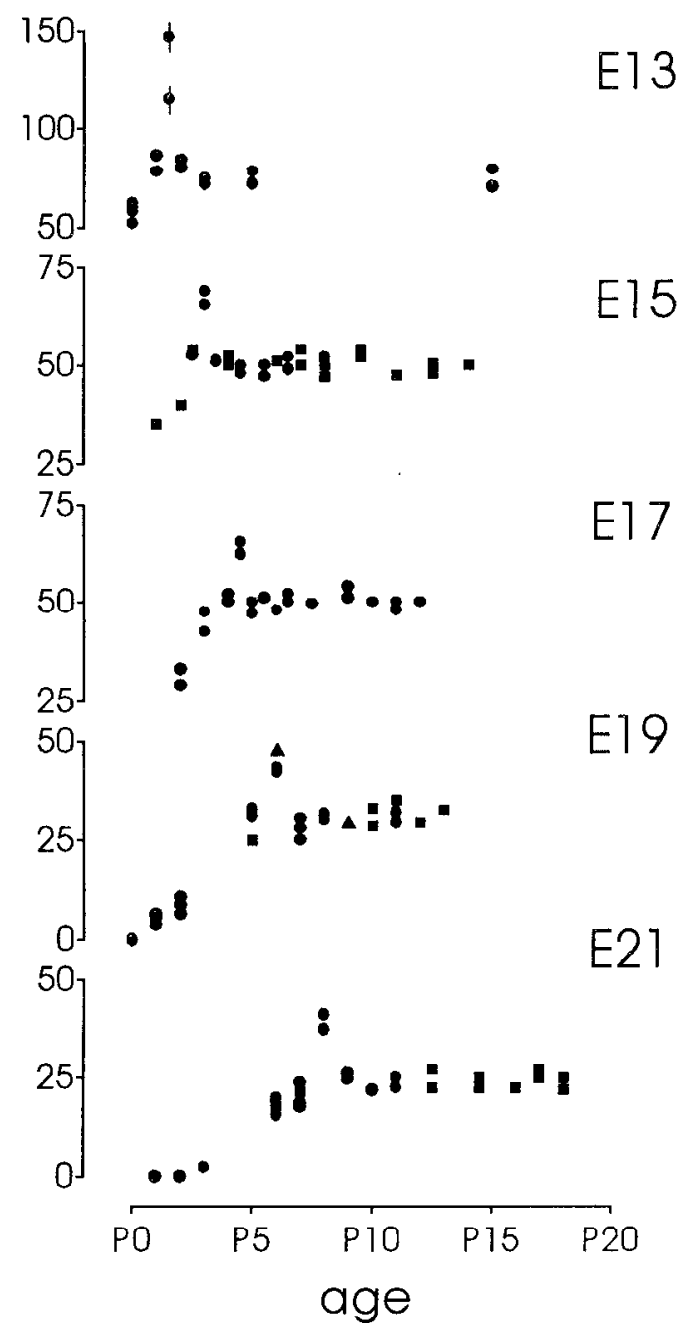

E13...E15E16...E18...E20...E22P1

E15........E19E20E21 ...P1P2P

E17.........E21E22P1P2P3P4

E19...E21E22P1P2P3P4P5P6

E21E22P1P2P3P4P5P6P7P8
Figure 2. a, BrdU pellets labeled cells born in an interval of $5 \mathrm{~d}$. In each row, the first day corresponds to the gestational age of BrdU pellet application. The following days are in boldface if BrdU-labeled mitotic figures were observed in the retina, and in normal type otherwise. Dots stand for ages that have not been tested. P1 is the day after birth. A minimum of two retinae were analyzed for each time point. $b$, Time course of the total number of cells in the GCL labeled after BrdU pellet application. Each graph reports the number of labeled cells found at different ages in the GCL of animals that received BrdU (pellet) at the same enbryonal age (specified on the right of each graph). In all cases, the number of labeled cells in the GCL increased during the 9-10 d after BrdU administration and dropped to a constant value the next day. Each point represents data obtained from a single retina, to illustrate experimental variability. Different symbols in a graph refer to data from different litters. The experimental crror attributable to variability in labeled cell density across the retina is exemplified by vertical bars for two cases in the E13 graph. The measures of the peak values were found statistically different from the data in the constant portion in all cases $(E 13: p<0.0001 ; E 15: p<0.0005 ; E 17: p<0.005$; E19: $p<0.005 ; E 21: p<0.005 ; t$ test). $c$, The number of labeled cells becomes constant $5 \mathrm{~d}$ after the end of labeled cell genesis. The first day in each row is the time of BrdU pellet administration, and the last day is the last day the number of labeled cells varies (corresponding to the time the number of labeled cells is maximal). $P 2 P$ is P2.5. The interval of labeled cell genesis is in boldface. 


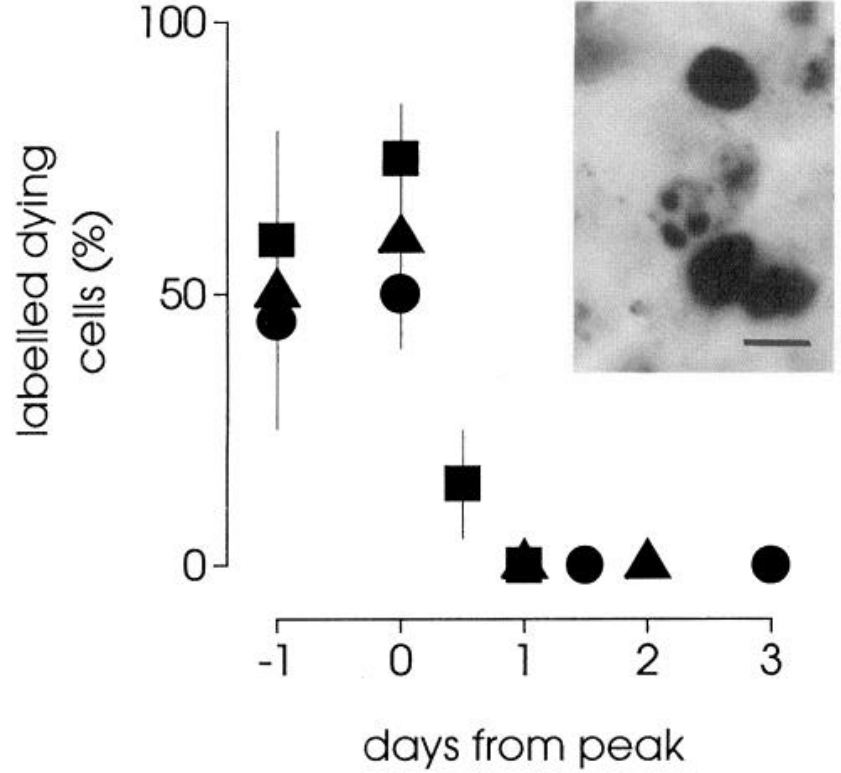

Figure 3. No dying labeled cell is observed once the number of labeled cells is constant. Time course of the fraction of pyknotic (dying) cells that were labeled with $\mathrm{BrdU}$ (expressed as percentage of the total number of pyknotic cells in the GCL). Data for the E17 injection (squares) and the $\mathrm{E} 13$ (circles) and E19 pellet (triangles) cases are illustrated. To normalize, the origin of the time scale corresponds in each case to the time the number of labeled cells in the GCL was maximal (last day in the corresponding row in Figs. $1 d$ and $2 c$ ). The inset shows a labeled pyknotic cell next to labeled cells. Scale bar, $4 \mu \mathrm{m}$.

\section{Most GCL neurons that die do so within $5 \mathrm{~d}$ of their genesis}

Labeled cells were first detected in the GCL $3 \mathrm{~d}$ after BrdU administration. Their number first increased before dropping to a constant value within a fixed interval after BrdU administration. A constant number of cells cannot be attributable to a prolonged balance between addition and attrition of cells. No labeled dying cells were seen after the number of labeled cells had reached a constant value, and no labeled cells were found migrating toward the GCL. Therefore, we conclude that a majority of cells that die do so within a constant interval from their genesis. This interval is $\sim 5 \mathrm{~d}$ irrespective of the time of cell birth and is likely to be the same for retinal ganglion cells and displaced amacrine cells, because it is independent of the cell composition of the single cohorts analyzed here.

Recent studies have shown that cell death could be the result of a suicide program, which developing neurons activate unless blocked by external signals such as trophic factors (Galli-Resta and Resta, 1992; Raff, 1992; Johnson and Deckwert, 1993; SilosSantiago et al., 1995). The existence of an intrinsic limiting time between genesis and death is consistent with this view, suggesting the presence of a cellular clock setting a maximal time for the activation of the death program.

It is important to consider that a limited number of cells could die beyond $5 \mathrm{~d}$ of their genesis, because a loss of $<20 \%$ of the final number of cells would be undetectable in our analysis. Reducing the experimental error would allow us to address this issue directly, but it may prove impossible with the present technique, because the main source of variability is interindividual variability, which is thought to be intrinsic for developing systems (Williams and Herrup, 1988). Certainly, experimental manipulations have been shown to rescue a limited amount of cells born $>5 \mathrm{~d}$ earlier

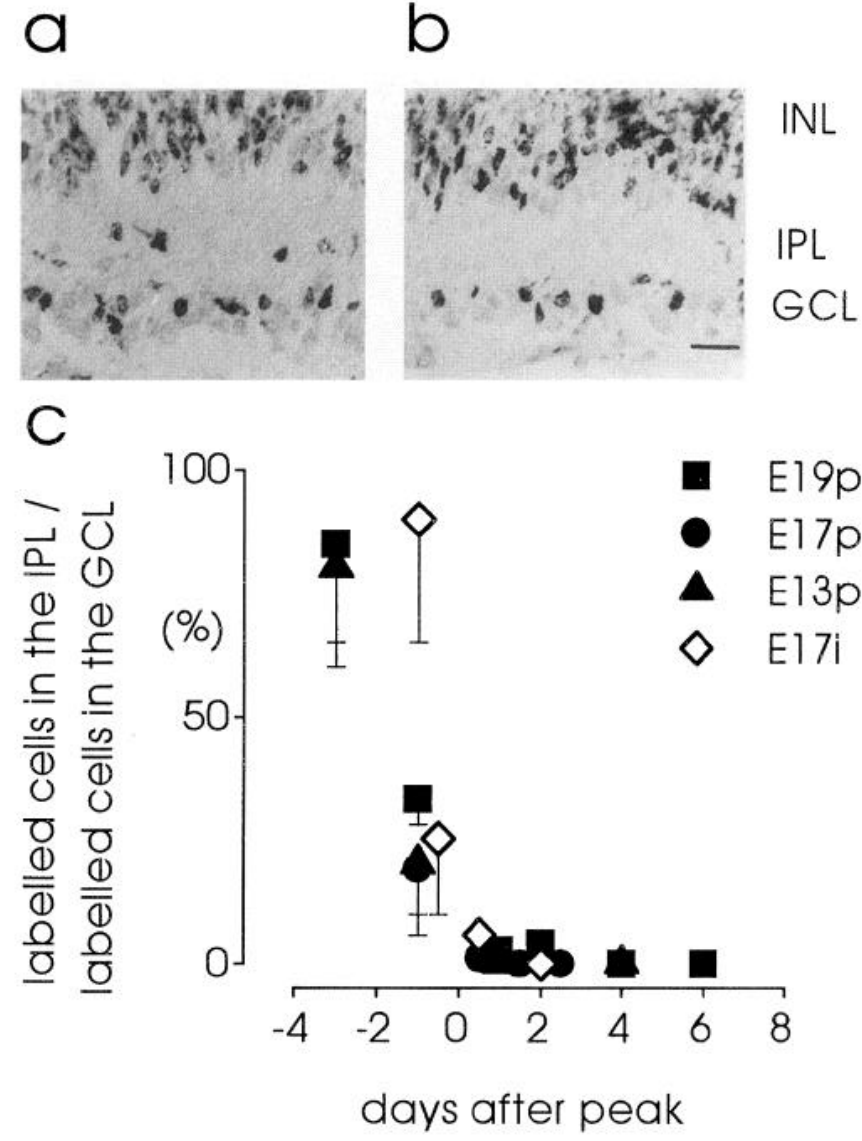

Figure 4. No more labeled cells reach the GCL once the number of labeled cells is constant. $a$, Before the number of labeled cells in the $G C L$ became constant, labeled cells were observed in the IPL, the plexiform layer that cells cross when migrating to the GCL (retinal cross-section of a P3 animal administered BrdU pellet on E17). $b$, Once the number of labeled cells became constant, no labeled cells were found in the IPL (P5 animal littermate of the case in $a$ ). $c$, Time course of the number of labeled cells found in the IPL (expressed as percentage of the total number of labeled cells in the GCL in the same retinal section). Data for the E17 injection $(i)$, and the E13, E17, and E19 pellet ( $p$ ) cases are illustrated. To normalize, the origin of the time scale corresponds in each case to the time the number of labeled cells in the GCL was maximal (last day in the corresponding row in Figs. $1 d$ and $2 c$ ). Thirty-two retinal sections from two retinae were analyzed for each time point. Scale bar, $10 \mu \mathrm{m}$. INL, Inner nuclear layer.

(Reese et al., 1992), which seems to lead support to the possibility that a limited contingent of cells is not governed by the rule of a $5 \mathrm{~d}$ maximal limit between genesis and death (see below).

The causes of cell death are still largely unknown, but a number of studies have shown the importance of target and afferent cells in rescuing developing neurons from death, leading to the view that apoptosis results from the competition of cells for limited amount of trophic substances and/or for limited synaptic space (see references in Oppenheim, 1981, 1991; Purves and Lichtman, 1985; Purves, 1988; Galli-Resta and Resta, 1992; Korsching, 1993). The question arises of how the finding of a limiting interval between genesis and death relates to this picture. A definitive answer cannot be given even in the well studied case of retinal ganglion cells, because the time it takes for axons of individual cells to reach their target has not yet been determined. However, more than twice as many cells as those found in the adult retina can be labeled by injecting a retrograde tracer in the ganglion cell 


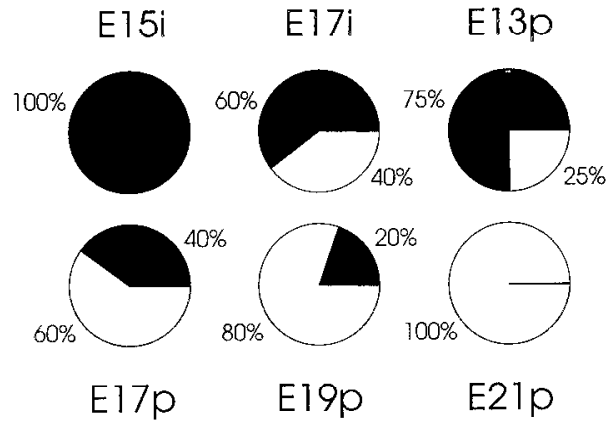

Figure 5. Different cohorts of labeled cells comprise different conbinations of the two neuronal types of the GCL, ganglion cells, and displaced amacrine cells. Pie charts illustrate the relative proportion of ganglion cells (black) and displaced amacrine cells (white) - expressed as percentage of the total number of labeled cells in the GCL-for each age and modality of BrdU administration ( $i$, injection; $p$, pellet). The analysis was restricted to retinae of adult rats that received BrdU during embryonal life. A $20 \%$ error affects these data.

target during development (Potts et al., 1982; Perry et al., 1983), suggesting that many rat retinal ganglion cells die after contacting their target. The same conclusion is reached by considering that the first retinal ganglion cells are generated on E14 in the rat (Reese and Colello, 1992), and the first retinal axons in the superior colliculus are detected on E16.5, less than $3 \mathrm{~d}$ later (Bunt et al., 1983). Indeed, Golgi studies show that ganglion cells can send out their axons while migrating to the GCL (Morest, 1970). Therefore, $5 \mathrm{~d}$ from genesis is likely to be an interval within which most retinal ganglion cells contact their target. This is almost certainly the case for amacrine cells that are located in close proximity to their target. Within this context, the specification of a fixed maximal life for neurons born during different time periods could act to reduce the disadvantage of late born cells among cells competing for limited resources. Furthermore, competition will be maximal, at any given moment, among cells born at the same time. This is because older cells will have past already their "deadline," whereas younger cells will be still far from their deadline. Several different functional types of retinal ganglion cells are present in the retina (for review, see Dowling, 1987), and cells of the same type tend to be born at the same time within any given region of the retina (Walsh et al., 1983; La Vail et al., 1991; Reese and Colello, 1992). Therefore, the presence of a limiting time interval between genesis and death might enhance competition among neurons of the same type, or even restrict it to them. This will occur even if all retinal ganglion cell types share the same target and most likely require the same trophic factors to survive.

An implication of the present results is that cell death might be a far more substantial phenomenon than currently believed. Indeed, while cell death is observed in the GCL for about 2 weeks, if neurons migrate to the GCL in no less than $3 \mathrm{~d}$, and a majority of those that die do so within $5 \mathrm{~d}$ of their genesis, most cells destined to die remain in the GCL for a maximum of $2 \mathrm{~d}$. Although this interval is likely to be the same for both ganglion cells and displaced amacrine cells, because it was the same for all cohorts that were composed of different proportion of the two cell types, further studies are required to solve this issue unequivocally. The total number of retinal ganglion cells declines from about 300,000 to little more than 100,000 in $12 \mathrm{~d}$ (Perry et al. 1983; Crespo et al., 1985). Assuming a cellular turnover of $2 \mathrm{~d}$ means that at each given time, a minimal estimate of the number of cells that will die within the next $2 \mathrm{~d}$ corresponds to the

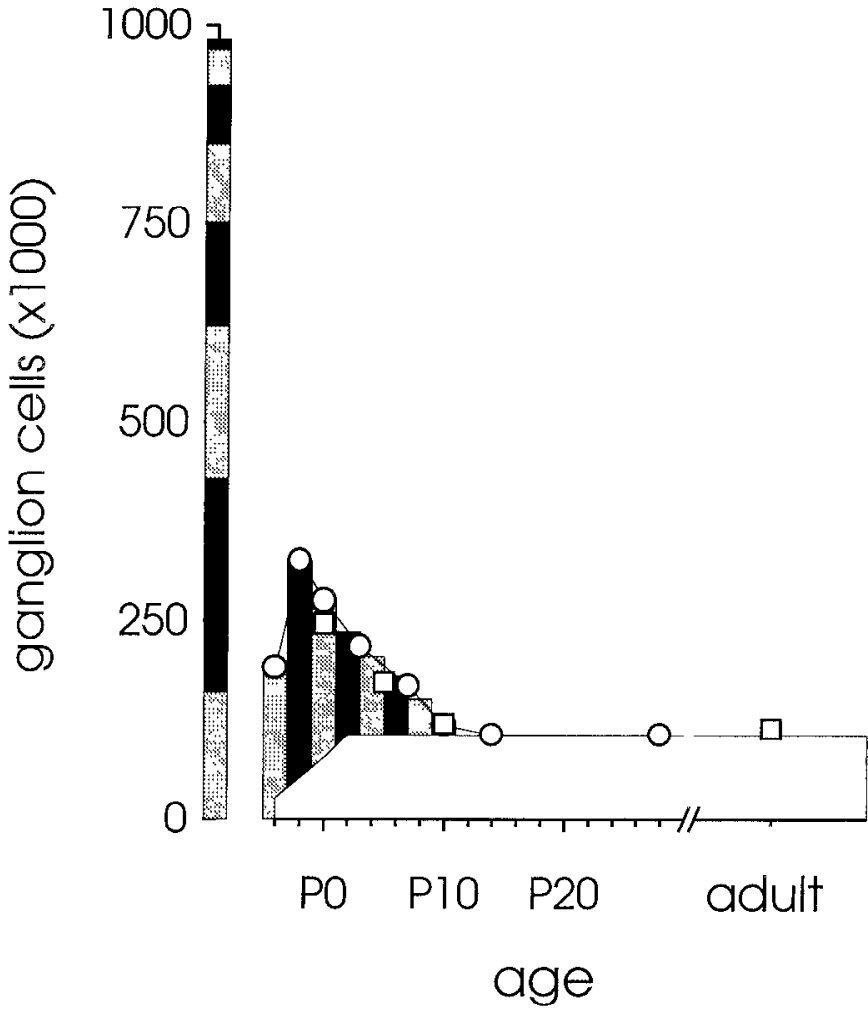

Figure 6. A cellular turnover of $2 \mathrm{~d}$ implies that at least $1,000,000$ ganglion cells die in the developing rat retina. Squares are data for the total number of rat retinal ganglion cells found at different ages as described by Perry et al. (1983), and circles are from Crespo et al. (1985). The curve delimiting the white area illustrates the gradual appearance of retinal ganglion cells surviving to adulthood. These cells are born between E14 and E20 (Reese and Colello. 1992) and reach the GCL between E17 and P1 or later, because we found that migration takes at least $3 \mathrm{~d}$. The number of cells that exceed those surviving to adulthood is computed at 2 $\mathrm{d}$ intervals and is represented by alternate black and gray bars. The sum of these values, illustrated by stacking the same bars along the ordinate axis, gives a minimal estimate of $1,000,000$ dying cells.

difference between the total number of retinal ganglion cells (Perry et al., 1983; Crespo et al., 1985), and the number of ganglion cells surviving to adulthood that have already reached the GCL [ganglion cells surviving to adulthood are generated between E14 and E20 (Reese and Colello, 1992) and reach the GCL between E17 and P1 or later, because migration takes at least $3 \mathrm{~d}$ ]. Taking the sum of the values obtained in this way at 2 d intervals (i.e., on E18, E20, E22, etc.) provides an estimate of at least 1,000,000 dying retinal ganglion cells (Fig. 6). This is fivefold greater than the estimates of the maximum number of dying ganglion cells provided by conventional counting methods. Similarly, an increase of a factor of 5 is obtained for the number of dying displaced amacrine cells based on data from Perry et al. (1983). These estimates would lead to an average clearance time for dying cells of $30 \mathrm{~min}$ to $1 \mathrm{hr}$, which corresponds to the clearance time for cells dying in C. elegans, the only case in which clearance has been directly observed (Ellis et al., 1991).

It remains to be established to what degree the findings of the present study can be generalized to other systems and to other species. Only experimental studies can address this issue, but it should be considered that in many instances, available data do not exclude the possibility that limited time intervals also exist for other cell types. Precise counts of the number of retinal ganglion 
cell axons performed throughout development in both monkey (Rakic and Riley, 1983a) and cat (Williams et al., 1986) show that the maximal number of axons is reached several days before the last growth cones are observed in the optic nerve, and these studies were among the first to suggest that cell death could be a much more conspicuous phenomenon than previously believed. A characteristic feature of the curves describing the decrease of the number of retinal ganglion cells is that they consist mainly of two phases, as do the curves describing death in many other developing neuronal populations [see Jacobson (1991) and references therein]. The total number of cells decreases at first very rapidly, as one would expect in the case of a limiting interval after genesis within which death occurs. A second phase follows in which a much more limited decrease is achieved during a longer temporal interval. Interestingly, experimentally induced increases in the total number of ganglion cells surviving death do not exceed the maximal number of cells found at the beginning of this late slow phase of normal cell decrease (cat: Williams et al., 1983; monkey: Rakic and Riley, 1983b; hamster: Sengelaub et al., 1983; rat: Crespo et al., 1985).

It is tempting to speculate that these two phases reflect two different processes - the early phase regulated by a limiting interval between genesis and death, and the late phase, not ruled by a temporal relationship between genesis and death (Reese et al., 1992), that could correspond to a "fine tuning" of cell death, allowing for numerical matching between connected structures (for review, see Galli-Resta and Resta, 1992), elimination of erroneous projections (Cowan et al., 1984), etc. Distinct phases of cell death would be consistent with current evidence showing that different neurotrophic factors may be accessible to particular neuronal populations in specific spatiotemporal sequences, so that several neurotrophic interactions may be required for normal development of a neuronal type (for review, see Korsching, 1993). The diffcrent phases of cell death could have different relevance in different neuronal populations, and the limiting intervals between genesis and death could vary from case to case. The validity of these concepts, which are readably testable, remains to be determined by future studies.

\section{REFERENCES}

Braekevelt CR, Hollenberg MJ (1970) The development of the retina of the albino rat. Am J Anat 127:281-302.

Bunt SM, Lund RD, Land PW (1983) Prenatal development of the optic projection in albino and hooded rats. Dev Brain Res 6:149-168.

Casini G, Brecha NC (1991) Vasoactive intestinal polypeptide containing cells in the rabbit retina: immunohistochemical localization and quantitative analysis. J Comp Neurol 305:313-327.

Cowan MW, Fawcett JW, O'Leary DDM, Stanfield BB (1984) Regressive events in neurogenesis. Science 225:1258-1265.

Crespo D, O'Leary DDM, Cowan WM (1985) Changes in the numbers of optic nerve fibres during late prenatal and postnatal development in the albino rat. Dev Brain Res 19:129-134.

Denham S (1967) A cell proliferation study of the neuronal retina in the two day old rat. J Embryol Exp Morphol 18:53-66.

Dowling JE (1987) The retina: an approachable part of the brain. Cambridge: Harvard UP.

Ellis RE, Yuan J, Horvitz HR (1991) Mechanisms and functions of cell death. Annu Rev Cell Biol 7:663-698.

Galli L, Maffei L (1988) Spontaneous impulse activity of rat retinal ganglion cells in prenatal life. Science 242:90-91.

Galli-Resta L, Resta G (1992) A quantitative model for the regulation of naturally occurring cell death in the developing vertebrate nervous system. J Neurosci 12:4586-4594.
Gratzner HG (1982) Monoclonal antibody to 5-bromo and 5-iododeoxyuridine: a new reagent for detection of DNA replication. Science 381:474-475.

Gravina A, Domenica L, Berarda N, Galli L, Maffei L (1990) Transplant of embryonal tissue preserves the responses of rat retinal ganglion cells after section of the optic nerve. Exp Brain Res 80:631-634.

Jacobson M (1991) Developmental neurobiology, 3rd Ed. New York: Plenum.

Johnson Jr EM, Deckwerth TL (1993) Molecular mechanisms of developmental neuronal death. Annu Rev Neurosci 16:31-46.

Korshing S (1993) The neurotrophic factor concept: a re-examination. J Neurosci 13:2739-2748.

La Vail MM, Rapaport DH, Rakic P (1991) Cytogenesis in the monkey retina. J Comp Neurol 309:86-114.

Martin DP, Schmidt RE, DiStefano PS, Lowry OH, Carter JG, Johnson EM (1988) Inhibitors of protein synthesis and RNA synthesis prevent neuronal death caused by nerve growth factor deprivation. J Cell Biol 106:829-844.

Morest DK (1970) The pattern of neurogenesis in the retina of the rat. Anat Entwickl Gesch 131:45-67.

Oppenheim RM (1981) Nenronal cell death and some related regressive phenomena during neurogenesis: a selective historical review and progress report. In: Studies in honour of Viktor Hamburger (Cowan WM, ed). New York: Oxford UP.

Oppenheim RW (1991) Cell death during development of the nervous system. Ann Rev Neurosci 14:453-501.

Pcrry VH (1981) Evidence for an amacrine cell system in the ganglion cell layer of the rat retina. Neuroscience 6:931-944.

Perry VH, Henderson Z, Linden R (1983) Postnatal changes in retinal ganglion and optic axon populations in the pigmented rat. J Comp Neurol 219:356-368.

Potts RA, Dreher B, Bennet MR (1982) The loss of ganglion cells in the developing retina of the rat. Dev Brain Res 3:481-486.

Purves D (1988) Body and brain: a trophic theory of neural connections. Cambridge: Harvard UP.

Purves D, Lichtman JW (1985) Principles of ncural development. Sunderland, MA: Sinauer.

Raff MC (1992) Social controls on cell survival and cell death. Nature 356:397-400.

Rakic P, Riley KP (1983a) Overproduction and elimination of retinal axons in the fetal rhesus monkey. Science 219:141-144.

Rakic P, Riley KP (1983b) Regulation of axon number in primate optic nerve by prenatal binocular competition. Nature 305:135 137.

Reese BE, Colello RJ (1992) Neurogenesis in the retinal ganglion cell layer of the rat. Neuroscience 46:419-429.

Reese BE, Colello RJ, Thompson WF (1992) Cell survival in the uncrossed projection of the mammalian retina is independent of birthdate. Eur J Neurosci 4:177-182.

Robinson SR (1991) Development of the mammalian retina. In: Vision and visual dysfunction, Vol 3 (Dreher B, Robinson R, eds). London: MacMillan.

Sengelaub DR, Windrem MS, Finlay BL (1983) Increased cell number in the adult hamster retinal ganglion cell layer after early removal of one eye. Exp Brain Res 52:269-276.

Silos-Santiago I, Greenlund LJS, Johnson EM, Snider WD (1995) Molecular genetics of neuronal survival. Curr Opin Neurobiol 5:42-49.

Villegas-Perez MP, Vidal-Sanz M, Rasminsky M, Bray GM, Aguayo AJ (1993) Rapid and protracted phases of retinal ganglion cell loss following axotomy in the optic nerve of adult rats. J Neurobiol 24:23-36.

Walsh C, Polley EH, Hickey TL, Guillery RW (1983) Generation of cat retinal ganglion cells in relation to central pathways. Nature 302:611-614.

Williams RW, Bastiani MJ, Chalupa LM (1983) Loss of axons in the cat optic nerve following fetal unilateral enucleation: an electromicroscopic analysis. J Neurosci 3:133-144.

Williams RW, Bastiani MJ, Lia B, Chalupa LM (1986) Growth cones, dying axons and developmental fluctuations in the fiber population of the cat's optic nerve. J Comp Neurol 246:32-69.

Williams RW, Herrup K (1988) The control of neuron number. Annu Rev Neurosci 11:423-453. 